\title{
Physico-chemical and quality characterization of pulp oil from two varieties of pili (Canarium ovatum Engl.) from Bicol, Philippines
}

\author{
${ }^{1,2}$ Tugay, M.M.D.R., ${ }^{1}$ Mopera, L.E., ${ }^{3}$ Esguerra, E.B. and ${ }^{1 *}$ Castillo-Israel, K.A.T. \\ ${ }^{1}$ Institute of Food Science and Technology, College of Agriculture and Food Science, University of the \\ Philippines Los Baños, College, Laguna, 4031 \\ ${ }^{2}$ College of Industrial Technology, Catanduanes State University, Calatagan, Virac, Catanduanes, 4800 \\ ${ }^{3}$ Postharvest Horticulture Training and Research Center, College of Agriculture and Food Science, \\ University of the Philippines Los Baños, College, Laguna, 4031
}

\section{Article history: \\ Received: 1 May 2020 \\ Received in revised form: 3 June 2020 \\ Accepted: 8 June 2020 \\ Available Online: 29 July \\ 2020}

\section{Keywords:}

Pili pulp oil,

M. Orolfo variety,

Orbase variety,

Fatty acid profile,

Coconut oil,

Extra virgin olive oil

DOI:

https://doi.org/10.26656/fr.2017.4(6).203

\begin{abstract}
This study aimed to characterize and compare pili (Canarium ovatum Engl.) pulp oil from two different varieties of pili fruits in Bicol, Philippines namely M. Orolfo and Orbase varieties for possible utilization into oil-based products. The effects of varietal differences in pili fruits on physical, chemical and quality characteristics of its pulp oil were determined. These two oils were also compared with control oils, commercially available coconut oil and extra virgin olive oil. Pili pulp oil from M. Orolfo had dark color while Orbase had color close to extra virgin olive oil. The two varieties did not significantly differ from each other in terms of refractive index, moisture and volatile matters, acid value, iodine value, saponification number and percent unsaponifiable matter but significantly differed from coconut oil and extra virgin olive oil. On the other hand, the two varieties significantly differed from each other in terms of peroxide value, Vitamin A and $\alpha$-tocopherol contents. In terms of fatty acid profile, high amounts of palmitic acid were determined in both pili varieties (19-25\%) compared with coconut oil (6.34\%). Oleic acid in Orbase was $71.5 \%$ while M. Orolfo had $58.1 \%$, which are comparable with extra virgin olive oil (77.9\%). Pili pulp oils from M. Orolfo and Orbase can be utilized into oilbased products because its chemical and quality characteristics are within the standard. Both can be stored for a longer period of time and healthier in terms of fatty acid composition and natural antioxidant content.
\end{abstract}

\section{Introduction}

Pili fruit is the most important nut-producing species and an indigenous fruit in the Philippines belonging to family Burseraceae. It is commonly known as a nut but is actually a drupe that is egg-shaped to oblong-shaped that weighs from 15.7 to 45.7 grams. Its pulp contains $73 \%$ moisture and is about $64.5 \%$ of the weight of the fruit. It contains a relatively high amount of fat, $33.6 \%$ based on the dry weight basis per 100 grams (Coronel, 1996).

Pili pulp oil (PPO) is a newly discovered source of vegetable oil in Bicol, Philippines that is now slowly making its way into the oil industry. It is very similar to olive oil in its chemical and nutritional properties; however, it contains more beta-carotene and carotenoids that make it more nutritious than olive oil (Asuncion, 2006). It is an inexpensive option to olive oil since its source is just a waste material from pili nut processing.

Pham and Dumandan (2015), reported that it has dark green color and the major fatty acids present in it are palmitic $(23.96 \%)$, palmitoleic $(4.66 \%)$, stearic $(2.64 \%)$, oleic $(60.93 \%)$ and linoleic $(6.63 \%)$. They also reported that the lipid molecular species present in the unsaponifiable matter of the said oil are carotenoids (141.79 mg/100 g oil), tocopherols (92.44 mg/100 g oil) and sterols $(1,009.61 \mathrm{mg} / 100 \mathrm{~g}$ oil $)$.

On the other hand, Coronel (1996), described PPO differently as clear oil with greenish yellow color containing $56.7 \%$ oleic glycerides, $13.5 \%$ linoleic glycerides and $29.3 \%$ saturated fatty acids.

Llenaresas (1989) extracted oil from fruit pulp of two pili varieties (Mabunga and Tree \#2) and characterized them in terms of specific gravity, refractive index, saponification value, iodine number, hydroxyl 
value and amount of unsaponifiable matter. Results show that pili pulp oil have a specific gravity of $0.9001-0.993$, a refractive index of 1.4520-1.4625, a saponification value of 167-184, an iodine number of 70.2-70.3, hydroxyl value of 0.00 , and unsaponifiable matter content of $1.12-1.88 \%$. The fatty acid analysis shows that pili pulp oil contains $69.4-80.6 \%$ oleic acid, $13.5-19.6 \%$ palmitic acid, 4.6-7.2\% linoleic acid, $0.01-1.01 \%$ stearic, and a small amount of palmitoleic acid. Results also show that the two oils resemble palm oil in terms of fatty acid composition, saponification value and degree of unsaturation and thus may be a good substitute for palm oil. PPO was also found to be high in carotene and tocopherols and considerable amounts of sterols, hydrocarbons and xantophylls (Pham, 2014).

There are several studies conducted regarding the effect of varietal differences on characteristics of different specific commodity. Gandul-Roxas and Minguez-Mosquera (1996) reported that variety is one of the factors that affect the chlorophyll and carotenoid pigments present in nine varieties of virgin olive oils from main Spanish producing regions. Helyes et al. (2012) reported that carotenoid content and composition of tomato fruits were also significantly affected by varietal factors. Kiritsakis (1998) reported that cultivar influenced flavor components of olive oil.

To date, there is no study yet on the effect of varietal differences in pili fruits on the characteristics of its pulp oil. Thus, this study aimed to determine and compare the characteristics of PPO from two different varieties of pili fruits from Bicol, Philippines for possible utilization into oil-based products. It is also the objective of this study to compare these PPO samples with two control oils, commercially available coconut oil and extra virgin olive oil.

\section{Materials and methods}

\subsection{Procurement of raw material for oil extraction}

Mature fruits of two varieties of pili fruits, (M. Orolfo and Orbase) were obtained from the Department of Agriculture, ARDC, Mayon Crossing, Tabaco City, Albay, Philippines. Fruits were placed in net bags $(37 \mathrm{~cm}$ x $35 \mathrm{~cm}$ ) and were transported to PHTRC, UPLB, Los Baños, Laguna and immediately stored in cold room at $10^{\circ} \mathrm{C}$.

\subsection{Extraction of pulp oil from two pili fruit varieties}

A total of 900 pieces of fresh pili fruits from each pili fruits variety (M. Orolfo and Orbase) were used in pulp oil extraction. Each pili fruit variety was divided into three lots, each representing one replicate. Each pili replicate was extracted with oil using the method of oil extraction in Figure 1 using 1:3 w/w of pulp to water ratio.

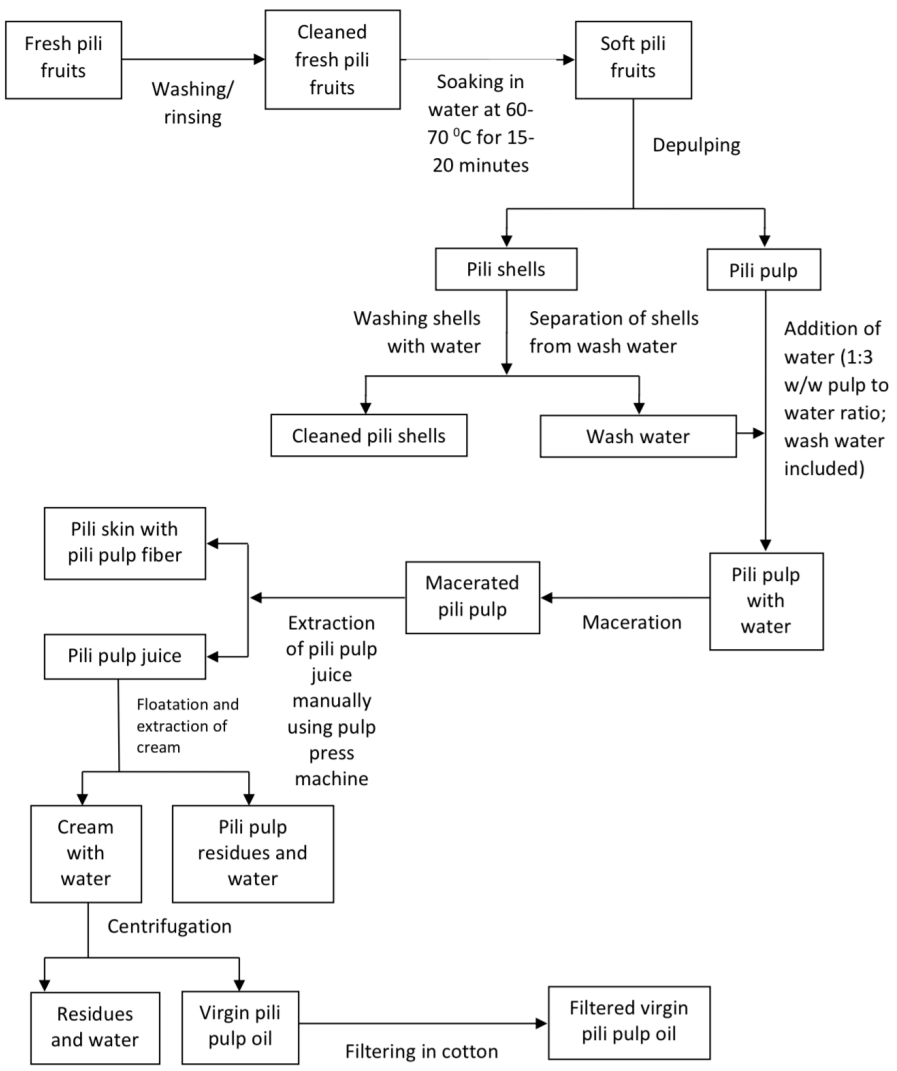

Figure 1. Process Flow for Pili Pulp Oil Extraction. Adapted from Pili oil extraction technology in DOST-V by Asuncion (2006).

\subsection{Characterization of oils}

Characteristics of pili pulp oil extracted from each replicate of each pili fruit variety were then determined in two trials. Commercially available refined coconut oil and extra virgin olive oil served as control oils.

\subsubsection{Physical characteristics}

To determine color values $\left(\mathrm{L}^{*}, \mathrm{a}^{*}, \mathrm{~b}^{*}, \mathrm{C}^{*}\right.$ and $\left.{ }^{\circ} \mathrm{H}\right)$, oil samples were packed in polyethylene bags and then sealed, ensuring no air bubbles were trapped inside. Color values $\left(\mathrm{L}^{*}, \mathrm{a}^{*}, \mathrm{~b}^{*}, \mathrm{C}^{*}\right.$ and $\left.{ }^{\circ} \mathrm{H}\right)$ were determined under a white background using color reader (CR-10, Konica Minolta, Optics Inc., Japan) with hole diameter of $0.75 \mathrm{inch}$. Meanwhile, specific gravity and refractive index were determined according to the AOAC method (2016).

\subsubsection{Chemical characteristics}

Chemical characteristics such as iodine value, saponification number, fatty acid profile and unsaponifiable matter were determined according to AOAC methods (2016). 


\subsubsection{Quality characteristics}

Quality characteristics such as moisture and volatile matter, acid value, peroxide value, Vitamin $\mathrm{A}$ and Vitamin E content were determined according to AOAC methods (2016).

\subsection{Experimental design}

This study employed a complete randomized design (CRD). Each treatment was triplicated while each of the analysis for each treatment was conducted in two trials.

\subsection{Statistical treatment of the data}

In a completely randomized design, Analysis of Variance (ANOVA), utilizing STAR software 2.0.1.2014 system, was used to determine if significant difference among mean scores exists and LSD was used to locate the differences among means. Q-test was used to determine the outlier.

\section{Results and discussion}

\subsection{Physical characteristics}

Physical characteristics of different types of oil are shown in Table 1. As shown, physical characteristics, in terms of color, specific gravity and refractive index, of different types of oil vary among each other, except for the $\mathrm{L}^{*}$ values of extra virgin olive and PPO from M. Orolfo, and refractive indices of the two PPO samples.

Varietal differences in pili fruits affect its pulp oil color in terms of lightness $\left(\mathrm{L}^{*}\right)$, chroma $\left(\mathrm{C}^{*}\right)$ and hue angle $\left({ }^{\circ} \mathrm{H}\right)$. When compared to that from Orbase variety, PPO from M. Orolfo variety has lower $L^{*}$ value, $C^{*}$ value and ${ }^{\circ} \mathrm{H}$ value. This implies that the latter has a darker and less intense color than that from Orbase variety. PPO from $\mathrm{M}$. Orolfo variety has an $\mathrm{L}^{*}$ value that is not significantly different from that of extra virgin olive oil but significantly lower than that of refined coconut oil. It has a $C^{*}$ value that is significantly lower than that of extra virgin olive oil but significantly higher than that of refined coconut oil. Its ${ }^{\circ} \mathrm{H}$ value is significantly higher than that of extra virgin olive oil but significantly lower than that of refined coconut oil.

On the other hand, PPO from Orbase variety has an
$\mathrm{L}^{*}, \mathrm{C}^{*}$ and ${ }^{\circ} \mathrm{H}$ values that are significantly higher than that of extra virgin olive oil and $\mathrm{L}^{*}$ and ${ }^{\circ} \mathrm{H}$ values that are significantly lower than that of refined coconut oil. It has a $C^{*}$ value that is significantly higher than that of refined coconut oil.

It is also shown in Table 1 that all of the oil samples have negative $a^{*}$ value and positive $b^{*}$ values. This means that the hue value of all these samples is within green $\left(-a^{*}\right)$ and yellow $\left(+b^{*}\right)$ zone. This implies the presence of carotenoid and chlorophyll pigments in the oil samples. Gandul-Roxas et al. (2016) and MinguezMosquera et al. (1990) reported that carotenoids and chlorophyll are mainly responsible for the color of virgin olive oils. Mounts (1981) also reported the presence of chlorophyll and a more prevalent and most important provitamins pigments in soybean oil, $\beta$-carotene. The said author also reported that the latter pigment is responsible for the red color of palm oil when present in higher concentration. Sahari et al. (2004) also attributed to the presence of carotenoids in the intensely yellow color of tea seed oil. Moyano et al. (2008) determined the relationship of color of virgin olive oils with their chlorophyll and carotenoid indices. Pearson coefficients $\left(r^{*}\right)$, revealed that that the best correlations are between the carotenoid index and the $\mathrm{C}^{*}\left(\mathrm{r}^{*}=0.801\right)$ values and $b^{*}\left(r^{*}=0.802\right)$ values. When compared with PPO, however, this high positive correlation is not evident. It can be observed in Table 4 that pulp oil from M. Orolfo variety has higher carotenoid (Vitamin A) content than that from Orbase variety but based on Table 1, the former has lower $C^{*}$ and $b^{*}$ values than the latter. This indicates how other pigments, aside from carotenoid, affect the $\mathrm{C}^{*}$ and $\mathrm{a}^{*}$ values in PPO samples. Figure 2 shows the actual appearance of the PPO and other oils. Darkest color was obtained from M. Orolfo while Orbase was almost similar in appearance to extra virgin olive oil. Meanwhile, Gandul-Roxas and Minguez-Mosquera (1996) reported that aside from variety, ripening degree of fruit affects the chlorophyll and carotenoid pigments present in nine varieties of virgin olive oils from main Spanish producing regions. They further reported that pheophytin (44-58\%) was the predominant pigment in all of the oils studied, followed by lutein (18-38\%) and $\beta$ carotene (6-17\%). Psomiadou and Tsimidou (2001) also reported that pheophytin $a$ was the main pigments in all

Table 1. Physical characteristics of different types of oil

\begin{tabular}{|c|c|c|c|c|c|c|c|}
\hline \multirow{3}{*}{ Types of Oil } & \multicolumn{7}{|c|}{ Physical Characteristics } \\
\hline & \multicolumn{5}{|c|}{ Color } & \multirow{2}{*}{$\begin{array}{l}\text { Specific } \\
\text { Gravity }\end{array}$} & \multirow{2}{*}{$\begin{array}{c}\text { Refractive } \\
\text { index at } 25^{\circ} \mathrm{C}\end{array}$} \\
\hline & $\mathrm{L}^{*}$ & $a^{*}$ & $b^{*}$ & $\mathrm{C}^{*}$ & ${ }^{\circ} \mathrm{H}$ & & \\
\hline Refined coconut oil & $78.87 \mathrm{a}$ & $-1.38 b$ & $14.18 \mathrm{~d}$ & $14.30 \mathrm{~d}$ & $95.47 \mathrm{a}$ & $0.9158 \mathrm{a}$ & $1.4551 \mathrm{c}$ \\
\hline Extra virgin olive oil & $66.63 \mathrm{c}$ & $-0.42 \mathrm{a}$ & $70.63 b$ & $70.60 \mathrm{~b}$ & $90.35 d$ & $0.9102 d$ & $1.4674 \mathrm{a}$ \\
\hline Pili pulp oil (M. Orolfo variety) & $66.13 \mathrm{c}$ & $-1.68 c$ & $41.33 \mathrm{c}$ & $41.38 \mathrm{c}$ & $92.37 \mathrm{c}$ & $0.9115 b$ & $1.4663 b$ \\
\hline Pili pulp oil (Orbase variety) & $73.53 b$ & $-5.17 d$ & $71.87 \mathrm{a}$ & $72.07 \mathrm{a}$ & $94.12 b$ & $0.9110 \mathrm{c}$ & $1.4663 b$ \\
\hline
\end{tabular}

Means followed by the same letter in a column are not significantly different from each other by LSD at $\alpha=0.05$ 
of 52 samples of virgin olive oils from various regions of Greece.

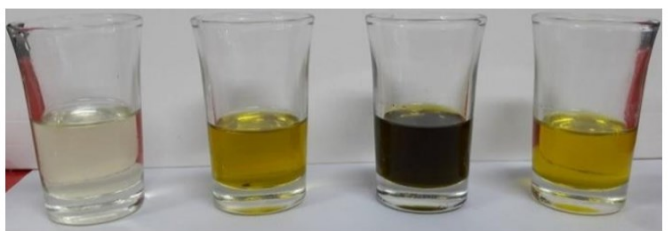

b

d

Figure 2. Different Types of Oil. (a) refined coconut oil, (b) extra virgin olive oil, (c) pili pulp oil (M. Orolfo variety), (d) pili pulp oil (Orbase variety)

Pulp oil extracted from M. Orolfo variety has higher specific gravity than from the one extracted from Orbase variety. This implies that varietal differences in pili fruit affect specific gravity of its pulp oil. Result of this study is similar to that of Llenaresas (1989) who reported varying specific gravity of pulp oil from two different varieties of pili extracted using the same solvent. It was further reported that there is a difference in specific gravity of PPO extracted from one variety of pili fruit by different solvents.

Table 1 also shows that the specific gravity of pili pulp oil samples varies from that of refined coconut oil and extra virgin olive oil. This observation can be explained by differences in the percentage of major fatty acid components of each oil samples (Table 3). Presence of more lauric acid (shorter chain) in a specified volume of refined coconut oil makes it heavier than fewer longer chains (oleic acid) in the same volume of PPO and extra virgin olive oil.

The refractive indices of two pili pulp samples are significantly higher than refined coconut oil but significantly lower than extra virgin olive oil. This result can be explained by differences in length and degree of unsaturation of fatty acid present. In Table 3, refined coconut oil is made up mostly of lauric acid while the biggest percentage of fatty acid in extra virgin olive oil and pili pulp oil is oleic acid. Moreover, extra virgin olive oil has a higher percentage of oleic acid than pili pulp oil, thus resulting in a higher refractive index in the former than the latter. Refractive index is the quotient between the speed of light in air and in oil being analyzed. It is affected by the length and degree of unsaturation of fatty acid, molecular weight and degree of conjugation (Ibeto et al., 2012). The higher the molecular weight of oil and length and degree of unsaturation of its fatty acid, the higher is the refractive index.

However, when compared with the results obtained from previous studies, refractive indices of pili pulp oil samples are higher than those reported by Pham and Dumandan (2015) and Llenaresas (1989). Extracted via enzymatic process, the former reported an index of refraction value of 1.4590 at $25^{\circ} \mathrm{C}$ while the latter reported a value of $1.4520-1.4625$ at $28^{\circ} \mathrm{C}$ for pulp oils from two different varieties of pili (Tree\#2 and Mabunga variety). The latter also reported that there is a slight difference in refractive indices of pulp oil samples extracted from the same variety of pili fruit by different solvents (chloroform-methanol and petroleum ether).

\subsection{Chemical characteristics}

In Table 2, the chemical characteristics of pulp oil samples from two pili varieties do not significantly vary from each other but both significantly vary from refined coconut oil and extra virgin olive oil.

Iodine value is a measure of an amount of iodine that can react with 100 parts of fat or oil (Baltes, 1964). It indicates unsaturation of fat and oils. The lower is the iodine value of fat, the lower is its degree of unsaturation, the lower its susceptibility to oxidation or vice versa (Sanders, 2003).

As shown in Table 2, iodine values of pili pulp oil samples are significantly higher than refined coconut oil but significantly lower than extra virgin olive oil. Reason for this is the higher percentage of saturated lauric oil in refined coconut oil and a higher percentage of unsaturated oleic acid in extra virgin olive oil than that of pili pulp oil samples (Table 3).

Based on iodine value, oils can be classified as drying oils (above $125 \mathrm{~g} \mathrm{I}_{2} / 100 \mathrm{~g}$ ), semi-drying oils (110$140 \mathrm{~g} \mathrm{I}_{2} / 100 \mathrm{~g}$ ) or nondrying oils (less than $110 \mathrm{~g} \mathrm{I}_{2} / 100$ g). Drying oil is most susceptible to oxidation (Ibeto et al., 2012). Table 2 shows that pili pulp oil along with refined coconut oil and extra virgin olive oil is classified as nondrying oil. This implies that this oil can be stored

Table 2. Chemical characteristics of different types of oil

\begin{tabular}{lccc}
\hline \multirow{2}{*}{ Types of Oil } & \multicolumn{3}{c}{ Chemical Characteristics } \\
\cline { 2 - 4 } & $\begin{array}{c}\text { Iodine value, } \mathrm{g} \\
\text { iodine/100 g sample }\end{array}$ & $\begin{array}{c}\text { Saponification number, } \\
\text { mg KOH/g fat }\end{array}$ & $\begin{array}{c}\text { Unsaponifiable } \\
\text { matter, \% }\end{array}$ \\
\hline Refined coconut oil & $14.44 \mathrm{c}$ & $253.50 \mathrm{a}$ & $0.3167 \mathrm{c}$ \\
Extra virgin olive oil & $83.62 \mathrm{a}$ & $187.39 \mathrm{~b}$ & $0.9017 \mathrm{a}$ \\
Pili pulp oil (M. Orolfo variety) & $69.10 \mathrm{~b}$ & $180.19 \mathrm{c}$ & $0.5283 \mathrm{~b}$ \\
Pili pulp oil (Orbase variety) & $72.70 \mathrm{~b}$ & $179.89 \mathrm{c}$ & $0.4783 \mathrm{~b}$ \\
\hline
\end{tabular}

Means followed by the same letter in a column are not significantly different from each other by LSD at $\alpha=0.05$ 
Table 3. Fatty acid profile of different types of oil

\begin{tabular}{lcccc}
\hline & \multicolumn{4}{c}{ Types of Oil } \\
\cline { 2 - 5 } Fatty Acid Profile, \%w/w & $\begin{array}{c}\text { Refined coconut } \\
\text { oil }\end{array}$ & $\begin{array}{c}\text { Extra virgin olive } \\
\text { oil }\end{array}$ & $\begin{array}{c}\text { Pili pulp oil } \\
\text { (M. orolfo variety) }\end{array}$ & $\begin{array}{c}\text { Pili pulp oil } \\
\text { (Orbase variety) }\end{array}$ \\
\hline Caproic (C6) & 0.543 & ND & ND & ND \\
Caprylic(C8) & 6.65 & ND & 0.046 & ND \\
Capric (C10) & 5.2 & ND & ND & ND \\
Lauric (C12) & 46.9 & 0.092 & 0.127 & 0.078 \\
Myristic (C14) & 19.9 & 0.025 & 0.183 & 0.132 \\
Myristoleic (C14:1) & ND & ND & ND & ND \\
Palmitic (C16) & 9.67 & 10.5 & 25.6 & 19.4 \\
Palmitoleic (C16:1) & ND & 0.96 & 5.61 & 2.76 \\
Stearic (C18) & 3.13 & 3.6 & 1.22 & 1.74 \\
Oleic (C18:1) & 6.34 & 77.9 & 58.1 & 71.5 \\
Linoleic (C18:2) & 1.61 & 5.81 & 7.8 & 3.96 \\
Linolenic (C18:3) & 0.027 & 0.552 & 1.23 & 0.349 \\
Erucic (C22:1) & ND & 0.7 & 0.039 & 0.019 \\
\hline
\end{tabular}

Legend: ND = None Detected

for a longer period since it is less prone to rancidity.

The iodine value of pili pulp oil (M. Orolfo variety) is lower but very close to the values reported by Llenaresas (1989). On the other hand, iodine value of pili pulp oil from Orbase variety lies in between the values obtained by Llenaresas (1989) and Pham and Dumandan (2015). The former reported a value ranging from 70.270.3 while the latter reported a value of 74.57. This variation can be attributed to varying methods of oil extraction and differences in variety among pili fruits.

Saponification number is the number of $\mathrm{mg}$ of $\mathrm{KOH}$ needed to neutralize and saponify the free and esterified organic acids, respectively in one gram of fat or oils (Baltes, 1964). It indirectly accounts the average molecular weight of the triglycerides of fat and oil (Bockisch, 1998). Saponification number of different types of oil is shown in Table 2. Pili pulp oil samples have significantly lower saponification number than extra virgin olive oil and refined coconut oil. This indicates that there are more triglycerides, which consist of fatty acids with longer carbon chain, present in pili pulp oil samples than that from the other two oils. When compared with other studies, saponification numbers of pili pulp oil samples are higher than that reported by Pham and Dumandan (2015) which is equivalent to 178 $\mathrm{mg} \mathrm{KOH} / \mathrm{g}$ and are within, though not equal to the range of values $(167-437 \mathrm{mg} \mathrm{KOH} / \mathrm{g})$ obtained by Llenaresas (1989) from pili pulp oil extracted from different varieties of pili fruits by different solvents. This implies that the method of oil extraction affects the fatty acid composition and as well as saponification number of oil. Moreover, Llenaresas (1989) pointed out also that aside from extracting solvents, the extent of oxidation or rancidity of oil also affects saponification value of pili pulp oil as carboxylic acids are produced when double bonds present in fatty acids of oils are attacked by oxygen.

Findings of Sahari et al. (2004) on the characteristics of tea seed oil in comparison to olive oil are different from this study. The iodine value of tea seed oil was significantly higher than olive oil, though the saponification value of the two mentioned oils was similar to each other.

Unsaponifiable matters are hydrophobic components that are stable towards bases and do not volatilize at $100^{\circ} \mathrm{C}$ like sterols, hydrocarbons, alcohols, mineral oils, carotenoids and the like (Baltes, 1964). Percent unsaponifiable matter in pili pulp oil samples is significantly higher than refined coconut oil but significantly lower than extra virgin olive oil (Table 2). The lower amount of unsaponifiable matter obtained from refined coconut oil is attributed to the refinement process undergone by this oil. Bleaching, as part of oil refinement processes, removes a wide range of different impurities like pigments and some oxidation products. Originally it was only used to reduce the oil color but nowadays, this step is done to get rid of or convert detrimental by-products to safe ones (Zschau, 2001). It usually improved the quality of oil with respect to color, oxidative stability and initial and aged flavor (Mounts, 1981). Moreover, lower amount of unsaponifiable matters in pili pulp oil than in olive oil implies higher purity of the former than the latter.

The amount of unsaponifiable matter obtained from pili pulp oil samples (Table 2) is way lower than that obtained by Pham and Dumandan (2015) and Llenaresas (1989). The former reported a mean value equivalent to $1.69 \%$ while the latter reported values ranging from $1.12 \%$ to $1.88 \%$ of unsaponifiable matters in pili pulp oil samples while for the samples is $0.4783 \%-0.5283 \%$. This result is attributed to the solvent used in the isolation of unsaponifiable matters. For this study, 
hexane is used as extracting solvent in the determination of unsaponifiable matters while the other mentioned researchers use diethyl ether. Solvents that are commonly used for the extraction of unsaponifiable matters are diethyl ether and light petroleum. The latter is usually preferred for vegetable oils because of the lesser tendency to form emulsions. However, in most of the cases, noticeable variations are observed in the result with the use of the two solvents since the extraction with light petroleum is incomplete (Tous, 1964). This indicates that the use of light petroleum, in the majority of cases, yields to lower results of total unsaponifiable matter than with the use of diethyl ether.

Table 3 shows the fatty acid profile of different types of oil. Oleic acid is the predominant fatty acid present in extra virgin olive oil and in both of the pili pulp oil samples while lauric acid for refined coconut oil. The total amount of saturated fatty acids in refined coconut oil is $91.993 \%$ while $14.217 \%-27.176 \%$ in extra virgin olive oil and both pili pulp oil samples. Meanwhile, the total amount of unsaturated fatty acids in the former is $7.977 \%$ while $72.779 \%-85.922 \%$ in the latter. This supports the lower refractive index $\left(1.455\right.$ at $\left.25^{\circ} \mathrm{C}\right)$ and iodine value (14.44) but higher saponification number (253.50) of the refined coconut oil as compared to 1.4663-1.4674 refractive indices at $25^{\circ} \mathrm{C}, 69.10-83.62$ iodine values and 179.80-187.39 saponification numbers of the three other oils.

The second most predominant fatty acid in pili pulp oil samples and extra virgin olive oils is palmitic acid while in refined coconut oil is myristic acid. Linoleic acid is the third most predominant fatty acid in pili pulp oil samples and extra virgin olive oil while for refined coconut oil is palmitic acid. These findings are different from the one reported by Borchani et al. (2010) when characteristics of sesame seeds and olive oils were compared. Linoleic acid was reported as the second most predominant fatty acid in both oils, next to oleic acid.

It is also observed that caprylic acid is the only fatty acid present in M. Orolfo variety that is not present in Orbase variety and extra virgin olive oil. Linolenic acid is higher in M. Orolfo variety than that from Orbase variety but stearic acid is higher in the latter than the former. Erucic acid is the lowest fatty acid components in both of the pili oil samples, while myristic and linolenic acid for extra virgin olive oil and refined coconut oil, respectively.

Same results were obtained by Llenaresas (1989), Colonel (1996), and Pham and Dumandan (2015), on the predominance of oleic acid in pili pulp samples studied. Colonel (1996) reported a value of 56.7\%; Pham and Dumandan (2015) reported a value of $60.93 \%$;
Llenaresas (1989) reported a value from 69.4-80.6 for the percentage of oleic acid from different pulp oil samples from different varieties by different solvents.

A difference in the fatty acid profile is also observed between the two pili pulp oil samples in Table 3. The same result is reported by Llenaresas (1989) about the fatty acid composition of two pulp oil samples extracted from Tree\#2 and Mabunga variety of pili fruits by two solvents. Llenaresas (1989) also reported that fatty acid composition of each pili pulp oil samples from two different varieties of pili also varies with the use of different extracting solvents (petroleum ether and chloroform-methanol). Abdolshahi et al. (2015) determined the fatty acid composition of pistachio oil extracted by two different conventional methods, Soxhlet extraction and maceration, each using four solvents with different polarities (n-hexane, dichloromethane, ethyl acetate and ethanol). Fatty acid profiles of pistachio oil were not affected by a different method of oil extraction but their contents were significantly affected with highest unsaturated fatty acid content (88.493\%) obtained by Soxhlet extraction with ethyl acetate. This was generally due to high operational temperature, solvent recycle and solvent/solute interaction. Tir et al. (2012) found that fatty acids, sterols and tocopherols extracted along with oil from Algerian sesame seeds vary due to differences in solvent polarity, thus leading to variation in the quality of the extracted oil. Carvalho et al. (2012) reported that fatty acid compositions significantly differ in sesame oils obtained by Soxhlet extraction using different solvents (ethanol and petroleum ether).

Aguilera et al. (2005) also reported the effect of environmental conditions on characteristics of virgin olive oils. It was found that the characteristics of virgin olive oils from two cultivars (Frantoio and Leccino) grown in two different locations significantly differs. Oils had higher oleic acid content and higher stability when the origin of its fruits are grown at higher altitude. In the open, oils had higher linoleic acid content and tocopherol content.

\subsection{Quality characteristics}

The quality characteristics of different types of oil are shown in Table 4. Significant differences exist among samples in terms of percent moisture and volatile matter, peroxide value, acid value, vitamin A content and vitamin E content.

In terms of moisture, pili pulp oil samples do not significantly differ from each other but both are significantly higher than the refined coconut and extra virgin olive oil. Comparing with the Codex Standard, the 
Table 4. Quality characteristics of different types of oil

\begin{tabular}{lccccc}
\hline \multirow{2}{*}{ Types of Oil } & \multicolumn{5}{c}{ Quality Characteristics } \\
\cline { 2 - 6 } & $\begin{array}{c}\text { Moisture and volatile } \\
\text { matters, } \%\end{array}$ & $\begin{array}{c}\text { Acid value, mg } \\
\text { KOH/g fat }\end{array}$ & $\begin{array}{c}\text { Peroxide value, meq. } \\
\text { peroxide/kg sample }\end{array}$ & $\begin{array}{c}\text { Vitamin A } \\
\text { content, I.U. }\end{array}$ & $\begin{array}{c}\text { dl- } \alpha \text { - tocopherol } \\
\text { content, } \mathrm{mg} / \mathrm{kg}\end{array}$ \\
\hline Refined coconut oil & $0.0367 \mathrm{~b}$ & $0.27 \mathrm{c}$ & $0.70 \mathrm{~d}$ & $41.22 \mathrm{~d}$ & $93.59 \mathrm{a}$ \\
Extra virgin olive oil & $0.0400 \mathrm{~b}$ & $0.75 \mathrm{a}$ & $10.38 \mathrm{c}$ & $165.73 \mathrm{~b}$ & $2.76 \mathrm{~b}$ \\
Pili pulp oil (M. Orolfo variety) & $0.1000 \mathrm{a}$ & $0.48 \mathrm{~b}$ & $13.50 \mathrm{~b}$ & $278.36 \mathrm{a}$ & $125.85 \mathrm{a}$ \\
Pili pulp oil (Orbase variety) & $0.0833 \mathrm{a}$ & $0.43 \mathrm{~b}$ & $14.58 \mathrm{a}$ & $123.00 \mathrm{c}$ & $2.45 \mathrm{~b}$ \\
\hline
\end{tabular}

Means followed by the same letter in a column are not significantly different from each other by LSD at $\alpha=0.05$

moisture and volatile matter content of both of the pili pulp oil samples are within the maximum level of $0.2 \%$ (Codex Alimentarius Commission, 1999). This implies that both of the pili pulp oil samples are in good quality and that the method used for its extraction is effective.

Moisture is an important quality parameter for oils because it is one of the reactants in oil hydrolysis. Oil hydrolysis yields free fatty acids which cause hydrolytic rancidity. Refined coconut oil in Table 4 has the lowest acid value because it has the lowest moisture content and because almost all of the non-fat components had been removed during refinement. However, pili pulp oil samples which have higher moisture content than extra virgin olive oil have lower acid value than the latter. Another factor which could affect acid value is the method of extraction. Virgin oils are obtained by pressing and application of heat while cold press oils are obtained by pressing only. Aside from its reactants and enzymes, oil requires heat to hydrolyze. Thus, the application of heat during extraction causes the acid value of the extra virgin oil sample to increase. Also, pressing of olive oils is not continuous, that filter mats could easily become contaminated which leads to the introduction of fermentation and oxidative defects into oils (Vossen, 2007).

In terms of acid value, the Codex Standard for refined coconut oil is up to $0.6 \mathrm{mg} \mathrm{KOH/gram} \mathrm{oil}$ (Codex Alimentarius Commission, 2001a), for virgin olive oil, it is up to $6.6 \mathrm{mg} \mathrm{KOH} /$ gram oil (Codex Alimentarius Commission, 2001b), and for other oils not covered by individual standards, it is up to $4.0 \mathrm{mg} \mathrm{KOH} /$ gram oil (Codex Alimentarius Commission, 1999). Therefore, it can be implied that all of the four oil samples are in good quality.

Peroxide value is one of the most important properties for determining the level of fat deterioration. It shows the molar equivalent of oxygen, bound as peroxide, which is present in one kilogram fat (Baltes, 1964).

All of the four oil samples significantly differ among each other in terms of peroxide value (Table 4). Orbase fruit variety has the highest peroxide value, followed by M. Orolfo variety and then by extra virgin olive oil.
Refined coconut oil sample obtained the lowest peroxide value. According to Zschau (2001), bleaching removes products of oxidation. Also, refined coconut oil is composed mostly of saturated fatty acid (Table 3) unlike pili pulp oil samples and extra virgin olive oil. Saturated fatty acids are less prone to oxidation than unsaturated ones (Sanders, 2003).

Akinoso et al. (2010) conducted a study on the effect of moisture on the peroxide value of unrefined sesame oil. Results revealed that peroxide value increased with increasing moisture content. The same result was found in this study. It is shown in Table 4 that moisture content of two pili pulp oil samples (with higher peroxide values) is significantly higher than that of refined coconut oil and extra virgin olive oil.

In terms of peroxide value, the Codex Standard for refined coconut oil is up to 10 milliequivalents of active oxygen per kilogram oil (Codex Alimentarius Commission, 2001a), for virgin olive oil, it is up to 20 milliequivalents of active oxygen per kilogram (Codex Alimentarius Commission, 2001b), and for other oils not covered by other individual standards, it is up to 15 milliequivalents of active oxygen per kilogram oil (Codex Alimentarius Commission, 1999). Therefore, it can be implied that all of the four oil samples are still in good quality.

When the two pili pulp oil samples are compared, it can be observed that the oil sample from M. Orolfo variety has a lower peroxide value than the other. This can be explained by the higher amount of unsaponifiable matters (Table 2) in M. Orolfo variety compared to the Orbase variety. Important natural antioxidants present in oil like Vitamin A and Vitamin E are unsaponifiable. It is shown in Table 4 that Vitamin A and Vitamin E components of $\mathrm{M}$. Orolfo are significantly higher than Orbase variety. Antioxidants help to reduce oxidation in oils. In fact, due to the high content of antioxidant, oils with high initial peroxide value may have unpredictably longer shelf-life (Tsimidou et al., 2003). Thus, it can be implied that M. Orolfo variety is less prone to oxidation than oil from Orbase variety because of the higher amount of natural antioxidant (Vitamin A and E) it contains. Sahari et al. (2004) also attributed to the presence of carotenoids and antioxidant activity of tea 
seed oil. Kamal-Eldin (2006) reported that the oxidative stability of vegetable oils is determined by fatty acid composition and presence of antioxidants, which are generally tocopherols and other non-saponifiable components. Based on this finding, it is recommended that further study should be made to determine the effect of fatty acid composition and antioxidant content of pili pulp oil from different varieties of pili fruits on its shelflife measured in terms of peroxide value.

Important antioxidants in oils, Vitamin $\mathrm{A}$ and $\mathrm{E}$ (as $\alpha$ -tocopherol), are shown in Table 4. It can be observed from Table 4 that $M$. Orolfo variety has the highest Vitamin A content, followed by extra virgin olive oil, Orbase variety and refined coconut oil, respectively. Vitamin A present in refined coconut oil comes from fortification done by the manufacturer. Its label declares that it contains around 61 I.U. of Vitamin A per gram oil. However, a mean value of 41.22 I.U. of Vitamin A per gram oil has been obtained from the analysis.

The varying Vitamin A content between two pili pulp oil samples may be due to varietal differences in pili fruits. Oil from Orbase variety has significantly lower Vitamin A content than extra virgin olive oil while that one from M. Orolfo variety is significantly higher than extra virgin olive oil.

The value of Vitamin A from two pili pulp oil samples are way lower than that reported by Pham and Dumandan (2015). These authors reported a value of $1417.9 \mu \mathrm{g}$ of carotenoids or 1181.58 I.U. of Vitamin A per gram of pili pulp oil. This may be due to the difference in the method used in the determination of the said component, varietal differences of pili fruits and method of oil extraction. This study utilized the hexane distillation method to determine the amount of unsaponifiable matters, wherein samples were refluxed for almost two hours. The refluxing process may have degraded some of the carotenoids in oil. Destruction of carotenoids in crude palm oil increased with both temperature and duration of exposure to heat (Fabien, et al., 2014). Onyewu et al. (1986) heated $10 \mathrm{~g} \beta$-carotene in glycerol at $210^{\circ} \mathrm{C}$ for $4 \mathrm{hrs}, 1 \mathrm{hr}, 15 \mathrm{mins}$, and $5 \mathrm{mins}$ and results showed that at $210^{\circ} \mathrm{C}$, degradation of $\beta$ carotene was almost complete after $4 \mathrm{hrs}$ and most of the nonvolatile products were viscous and yellow-brownish in color. Less degradation was observed at shorter times ( $1 \mathrm{hr}, 15 \mathrm{mins}$, and $5 \mathrm{mins}$ ). Aside from variety, other factors that affect carotenoid content in plant food are genotype, season, geographic location, climate, stage of maturity and growing conditions (Kocher et al., 2014). Aherne et al. (2009) reported that differences in type and geographical locations of tomato significantly affect its carotenoid content and bioaccessibility. Meanwhile,
Helyes et al. (2012) reported that carotenoid content and composition of tomato fruits were significantly affected by varietal factors and water supply. Kotikova et al. (2007) found that carotenoid content in potato tubers was significantly affected by maturity, year of cultivation and variety.

M. Orolfo variety has the highest $\alpha$-tocopherol content that is not significantly different from that of refined coconut oil. Presence of $\alpha$-tocopherol in refined coconut oil could mean that it is extracted from coconut meat with its testa. This claim is proven by Dia (2005). In order to prove that $\alpha$-tocopherol is present in coconut testa and not in coconut endosperm, the said author subjected both coconut testa and coconut milk to Vitamin E analysis. Results of this investigation revealed that the former contains $732 \mu \mathrm{g}$ tocopherol while the latter did not contain any.

On the other hand, both Orbase variety and extra virgin olive oil have a significantly lower content of $\alpha$ tocopherol than the two other oils. The varying $\alpha$ tocopherol content between two pili pulp oil samples may be due to differences in pili fruit variety. Aside from variety, Aguilera (2005) reported that the tocopherol content of virgin olive oil is affected by environmental conditions. The said author reported that the tocopherol content of virgin olive oil is lower when its fruit sources were grown in higher altitude. Values of $\alpha$-tocopherol content in two pili pulp oil samples are far lower than that reported by Pham and Dumandan (2015) which is $924 \mu \mathrm{g} \alpha$-tocopherol per gram of pili pulp oil. Possible reasons for this are different method used in the analysis of the said component, method of oil extraction, varietal differences of pili fruits used in the study and sample storage time. Rastrelli et al. (2002) reported a $20 \%$ and $92 \%$ decrease in $\alpha$-tocopherol content of olive oil after 2 months and 12 months, respectively of storage in the dark.

\section{Conclusion}

Characteristics of pili pulp oil samples from two varieties of pili (M. Orolfo and Orbase) were determined for possible utilization into oil-based products. Physical characteristics of pulp oil samples from two different varieties of pili fruits vary from each other and from commercially available oil samples, except for $\mathrm{L}^{*}$ values of extra virgin olive and PPO from M. Orolfo. Chemical characteristics of two pili pulp oil samples do not significantly vary from each other but both significantly vary from commercially available oil samples, except for refractive indices of the two PPO samples. Quality characteristics of two pili pulp oil samples significantly vary from commercially available oil samples. There is 
no significant difference between mean values of these characteristics of two pili pulp oil samples in terms of percent moisture content and acid value but a significant difference exists in terms of peroxide value, Vitamin A and $\alpha$-tocopherol content. PPO from M. Orolfo and Orbase can be utilized into oil-based products because of its chemical and quality characteristics are within the standard set by Codex Alimentarius Commission and both can be stored for a longer period of time. Also, these oils are healthier because most of the fatty acids present are unsaturated, containing a significant amount of natural antioxidants (Vitamin A and $\alpha$-tocopherol) and essential fatty acids (linoleic and linoleic acid).

\section{Conflict of interest}

The authors declare no conflict of interest.

\section{Acknowledgments}

The research work was funded by CHED K-12 scholarship program and Catanduanes State University, Virac, Catanduanes.

\section{References}

Abdolshahi, A., Majd, M.H., Rad, J.S., Taheri, M., Shabani, A. and Da Silva, J.A.T. (2015). Choice of solvent extraction technique affects fatty acid composition of pistachio (Pistacia vera L.) oil. Journal of Food Science and Technology, 52(4), 2422-2427. https://doi.org/10.1007/s13197-013-1183 $-8$

Aguilera, M.P., Beltrán, G., Ortega, D., Fernández, A., Jiménez, A. and Uceda, M. (2005). Characterisation of virgin olive oil of Italian olive cultivars: Frantoio'andLeccino', grown in Andalusia. Food Chemistry, 89(3), 387-391. https://doi.org/10.1016/ j.foodchem.2004.02.046

Aherne, S.A., Jiwan, M.A., Daly, T. and O'brien, N.M. (2009). Geographical location has greater impact on carotenoid content and bioaccessibility from tomatoes than variety. Plant Foods for Human Nutrition, 64(4), 250-256. https://doi.org/10.1007/ s11130-009-0136-x

Akinoso, R., Aboaba, S.A. and Olayanju, T.M.A. (2010). Effects of moisture content and heat treatment on peroxide value and oxidative stability of un-refined sesame oil. African Journal of Food, Agriculture, Nutrition and Development, 10(10), 4268-4285. https://doi.org/10.4314/ajfand.v10i10.62908

AOAC. (2016). Official Methods of Analysis of AOAC International. $20^{\text {th }}$ ed. USA: The Association of Agricultural Chemists

Asuncion, J.N. (2006). Pili Oil Extraction Technology in
DOST-V. Retrieved on July 28, 2013 from DOSTSTII Website:http://sntpost.stii.dost.gov.ph/ NewPOST/JanMar2006/Pili_oil_extraction.htmls

Baltes, J. (1964). Classical Methods in Fat Analysis. In Boekenoogen, H.A. (Ed.). Analysis and Characterization of Oils, Fats and Fat Products, p. 158. London: Interscience Publishers.

Bockisch, M. (1998). Fats and Oils Handbook. Germany: Elsevier Inc.

Borchani, C., Besbes, S., Blecker, C. and Attia, H. (2010). Chemical characteristics and oxidative stability of sesame seed, sesame paste, and olive oils. Journal of Agricultural Science and Technology, 12, 585-596.

Carvalho, R.H.R., Galvão, E.L., Barros, J.A.C., Conceição, M.M. and Sousa, E.M.B.D. (2012). Extraction, fatty acid profile and antioxidant activity of sesame extract (Sesamum Indicum L.). Brazilian Journal of Chemical Engineering, 29(2), 409-420. https://doi.org/10.1590/S0104-66322012000200020

Codex Alimentarius Commission. (1999). Codex standard for edible fats and oils not covered by individual standards. Codex Stan, 19, 1981. Rome

Codex Alimentarius Commission. (2001a). Codex standard for named vegetable oils. Codex Stan 2101999, 19-23. Rome

Codex Alimentarius Commission. (2001b). Codex standard for olive oil, virgin and refined, and for refined olive-pomace oil. Codex Stan, 825-839. Rome

Coronel, R.E. (1996). Pili Nut. Canarium ovatum Engl. Retrieved on May 18, 2018 from Pili Nut Canarium ovatum EnglWebsite: http://citeseerx.ist.psu.edu/ viewdoc/download?

doi $=10.1 .1 .506 .4492 \&$ rep $=$ rep $1 \&$ type $=$ pdf

Dia, V.P. (2005). Production and characterization of virgin coconut oil. Los Baños, Laguna: University of the Philippines Los Baños, MSc. Thesis.

Fabien, D.D.F., Annie, N.N., Adélaide, D.M., Florian, S. and Inocent, G. (2014). Effect of heating and of short exposure to sunlight on carotenoids content of crude palm oil. Journal of Food Processing and Technology, 5(4), 1000314.

Gandul-Rojas, B. and Minguez-Mosquera, M.I. (1996). Chlorophyll and carotenoid composition in virgin olive oils from various Spanish olive varieties. Journal of the Science of Food and Agriculture, 72(1), 31-39. https://doi.org/10.1002/ (SICI) 1097-0010(199609)72:1<31::AIDJSFA619>3.0.CO;2-5

Gandul-Rojas, B., Roca, M. and Gallardo-Guerrero, L. (2016). Chlorophylls and Carotenoids in Food Products from Olive Tree. InTechOpen E-Book. https://doi.org/10.5772/64688 
Helyes, L., Neményi, A., Pék, Z., Berki, M. and Daood, H.G. (2012). Effect of variety and water supply on phytochemical (phenolics and carotenoids) content and composition of processing tomato. ISHS Acta Horticulturae 971: XII International Symposium on the Processing Tomato, 971, 93-98. https:// doi.org/10.17660/ActaHortic.2013.971.8

Ibeto, C.N., Okoye, C.O.B. and Ofoefule, A.U. (2012). Comparative Study of the Physicochemical Characterization of Some Oils as Potential Feedstock for Biodiesel Production. International Scholarly Research Notices, 2012, 621518. https:// doi.org/10.5402/2012/621518

Kamal-Eldin, A. (2006). Effect of fatty acids and tocopherols on the oxidative stability of vegetable oils. European Journal of Lipid Science and Technology, 108(12), 1051-1061. https:// doi.org/10.1002/ejlt.200600090

Kiritsakis, A.K. (1998). Flavor components of olive oil-A review. Journal of the American Oil Chemists' Society, 75(6), 673-681. https:// doi.org/10.1007/s11746-998-0205-6

Kotikova, Z., Hejtmankova, A., Lachman, J., Hamouz, K., Trnkova, E. and Dvorak, P. (2007). Effect of selected factors on total carotenoid content in potato tubers (Solanum tuberosum L.). Plant Soil and Environment, 53, 355-360. https:// doi.org/10.17221/2214-PSE

Llenaresas, D.M. (1989). Characterization of pili (Canarium ovatum) pulp and nut oil. Los Baños College, Laguna: University of the Philippines Los Baños, BSc. Thesis.

Minguez-Mosquera, M.I., Gandul-Rojas, B., GarridoFernandez, J. and Gallardo-Guerrero, L. (1990). Pigments present in virgin olive oil. Journal of the American Oil Chemists' Society, 67(3), 192-196. https://doi.org/10.1007/BF02539624

Mounts, T.L. (1981). Chemical and physical effects of processing fats and oils. Journal of the American Oil Chemists' Society, 58(1), 51A-54A. https:// doi.org/10.1007/BF02666073

Moyano, M.J., Meléndez-Martínez, A.J., Alba, J. and Heredia, F.J. (2008). A comprehensive study on the colour of virgin olive oils and its relationship with their chlorophylls and carotenoids indexes (II): CIELUV and CIELAB uniform colour spaces. Food Research International, 41(5), 513-521. https:// doi.org/10.1016/j.foodres.2008.03.006

Onyewu, P.N., Ho, C.T. and Daun, H. (1986). Characterization of $\beta$-carotene thermal degradation products in a model food system. Journal of the American Oil Chemists' Society, 63(11), 1437-1441. https://doi.org/10.1007/BF02540870

Pham, L.J. (2014). Establishment of bioprocess system for the production of pili pulp oil and protein enriched residue for the food and feed industries (Project 3). Los Baños College, Laguna: National Institute of Molecular Biology and Biotechnology, University of the Philippines Los Baños

Pham, L.J. and Dumandan, N.G. (2015). Philippine Pili: Composition of the lipid molecular species. Journal of Ethnic Foods, 2(4), 147-153. https:// doi.org/10.1016/j.jef.2015.11.001

Psomiadou, E. and Tsimidou, M. (2001). Pigments in Greek virgin olive oils: occurrence and levels. Journal of the Science of Food and Agriculture, 81(7), 640-647. https://doi.org/10.1002/ jsfa. 859

Rastrelli, L., Passi, S., Ippolito, F., Vacca, G. and De Simone, F. (2002). Rate of degradation of $\alpha$ tocopherol, squalene, phenolics, and polyunsaturated fatty acids in olive oil during different storage conditions. Journal of Agricultural and Food Chemistry, 50(20), 5566-5570. https:// doi.org/10.1021/jf011063j

Sahari, M.A., Ataii, D. and Hamedi, M. (2004). Characteristics of tea seed oil in comparison with sunflower and olive oils and its effect as a natural antioxidant. Journal of the American Oil Chemists' Society, 81(6), 585-588. https://doi.org/10.1007/ s11746-006-0945-0

Sanders, T.H. (2003). Ground Nut Oil. Retrieved on March 25, 2019 from Science Direct Website: https://www.sciencedirect.com/topics/biochemistrygenetics-and-molecular-biology/iodine-value

Tir, R., Dutta, P.C. and Badjah-Hadj-Ahmed, A.Y. (2012). Effect of the extraction solvent polarity on the sesame seeds oil composition. European Journal of Lipid Science and Technology, 114(12), 14271438. https://doi.org/10.1002/ejlt.201200129

Tous, J. (1964). Chemistry and analysis of olive oil. In Analysis and characterization of oils, fats and fat products. Vol. 2, p. 315-606. London: Interscience Publishers.

Tsimidou, M., Blekas, G. and Boskou, D. (2003). Olive Oil. In Caballero, B. (Ed.) Encyclopedia of Food Sciences and Nutrition. $2^{\text {nd }}$ ed. USA: Academic Press. $\quad$ https://doi.org/10.1016/B0-12-227055$\mathrm{X} / 01347-\mathrm{X}$

Vossen, P. (2007). Olive oil: history, production, and characteristics of the world's classic oils. HortScience, 42(5), 1093-1100. https:// doi.org/10.21273/HORTSCI.42.5.1093

Zschau, W. (2001). Bleaching of edible fats and oils. European Journal of Lipid Science and Technology, 103(8), 505-551. https:// doi.org/10.1002/1438-9312(200108)103:8<505::AID -EJLT505>3.0.CO;2-7 